\title{
DETERMINATION OF SPRAY DRIFT USING MULTIPLE METAL CATIONS AS TRACERS
}

\author{
J.A. ZABKIEWICZ ${ }^{1}$, K.D. STEELE ${ }^{1}$ and J.P. PRAAT ${ }^{2}$ \\ ${ }^{1}$ Plant Protection Chemistry ${ }_{N Z}$, PO Box 6282, Rotorua, New Zealand \\ ${ }^{2}$ Lincoln Ventures Ltd, PB 3062, Hamilton, New Zealand \\ Corresponding author:jaz@ppcnz.co.nz
}

\begin{abstract}
An alternative method to the use of dyes in spray drift estimation has been developed using different metal cations with each spray solution. This removes the need to collect the targets until all the spray events have been completed. Spray drift trials were conducted with a tractor plus boom over a grass sward with plastic tape as the collector to capture ground spray deposits. The extracted deposits from the collectors were quantified by ICP-MS. The advantages of using cations are that they are stable, very low levels of detection are possible, analytical and operational costs are reduced and they are non-phytotoxic at operational amounts. Keywords: spray drift, metal cations, cation analysis, deposition profiles, boom sprayer.
\end{abstract}

\section{INTRODUCTION}

Agrichemical spray drift measurement may be determined by the amount of the active ingredient (ai) deposited downwind of the target area. In research trials involving multiple applications under similar or different conditions, this can be expensive, laborious and limits the sites available. An alternative method is to use a tracer instead of an ai, either visible or fluorescent dyes, which can be easily recovered and quantified by spectroscopic methods (Ucar et al. 2003; Brown et al. 2004; Gil \& Sinfort 2005). The disadvantage of this method is that it is difficult to find multiple dyes that can be analysed without interference from the others, so they are typically used alone, meaning that the sampling traps or foliage need to be recovered after each application. Recently there have been a few reports of the use of metal salt solutions as the tracer (Cross et al. 2001; Brusselman et al. 2004; Thistle et al. 2007), which have the advantage that multiple applications can be undertaken onto the same target needing only a single recovery procedure at the end of the spray events. This analytical approach has been used in a programme that is evaluating the validity and applicability of the ground boom spraying option in AGDISP (Teske et al. 2001). This paper describes the experimental and operational requirements for such a trial, illustrated by a sub-set of results from the metal cation tracers as analysed by inductively coupled plasma mass spectrometry (ICP-MS). A comparison of experimental results with calculated AGDISP depositions is presented elsewhere (Woodward et al. 2008).

\section{Chemicals}

\section{MATERIALS AND METHODS}

Spray solutions were made up in distilled water with metal salts at the concentrations below (Table 1) plus $0.1 \% \mathrm{v} / \mathrm{v}$ of Bond Xtra (Elliott Technologies Ltd). Acidic solutions were brought to $\mathrm{pH}$ 6.5-7.0 by the addition of ammonia.

\section{Chemical analyses}

Collection of tapes was at the end of the series of spray events. Three approximately $90 \mathrm{~cm}$ lengths were cut from the total $3 \mathrm{~m}$ length and used as replicate collectors. The plastic tapes were measured to correct for length variation and the actual surface area calculated for each. The pieces were put in plastic bags, and subsequently an appropriate 
volume (50 or $100 \mathrm{ml}$ ) of $1 \%$ nitric acid solution added, the wash solution decanted and sub-samples despatched for analysis. All samples were analysed by R.J. Hill Laboratories using ICP Mass spectrometry. Individual analytical results were converted from cation ppm values to $\mu \mathrm{g} / \mathrm{cm}^{2}$ and the mean of the three replicates was used to calculate the percentage of spray deposited. Prior to the trial, samples of tapes were extracted in the same manner to determine cation background levels as well as recovery of cation material from known applications. A known volume (50 x $2 \mu$ l droplets) of each cation solution was applied by microsyringe onto sections of tape. These deposits were allowed to dry $(2 \mathrm{~h})$ and then the residues washed off to determine the extraction efficiency.

TABLE 1: Treatments, concentrations and limits of detection by ICP-MS for selected salt solutions

\begin{tabular}{lccccrc}
\hline $\begin{array}{l}\text { Treatment } \\
\text { No. } \\
\text { (Nozzle) }\end{array}$ & $\begin{array}{c}\text { No. } \\
\text { swathes }\end{array}$ & Cation & Salt & $\begin{array}{c}\text { Concentration } \\
\text { salt in spray } \\
(\mathrm{g} / \text { litre })\end{array}$ & $\begin{array}{c}\text { Concentration } \\
\text { cation in spray } \\
(\mathrm{ppm})\end{array}$ & $\begin{array}{c}\text { Limit of } \\
\text { detection } \\
(\mathrm{ppm})\end{array}$ \\
\hline $1(11004)$ & One & $\mathrm{Ba}$ & $\mathrm{BaNO}_{3}$ & 0.4 & 210 & 0.0001 \\
$2(11004)$ & Four & $\mathrm{Co}$ & $\mathrm{Co}\left(\mathrm{NO}_{3}\right)_{2} \cdot 6 \mathrm{H}_{2} \mathrm{O}$ & 0.4 & 82 & 0.0002 \\
$3(11003)$ & One & $\mathrm{Cu}$ & $\mathrm{Cu}\left(\mathrm{NO}_{3}\right)_{2}$ & 0.4 & 105 & 0.0005 \\
$4(11003)$ & Four & $\mathrm{K}$ & $\mathrm{KCl}_{3}$ & 40 & 20978 & 0.05 \\
$5(11004)$ & One & $\mathrm{Li}$ & $\mathrm{Li}\left(\mathrm{NO}_{3}\right) \cdot 3 \mathrm{H}_{2} \mathrm{O}$ & 0.8 & 131 & 0.0002 \\
$6(11004)$ & Four & $\mathrm{Mn}$ & $\mathrm{MnCl}_{2}$ & 0.4 & 111 & 0.0005 \\
$7(11003)$ & One & $\mathrm{Se}$ & $\mathrm{SeO}_{2}$ & 0.4 & 283 & 0.001 \\
$8(11003)$ & Four & $\mathrm{Mg}$ & $\mathrm{Mg}\left(\mathrm{Cl}_{2}\right.$ & 25.1 & 6407 & 0.02 \\
\hline
\end{tabular}

\section{Experimental site and layout}

The trial was conducted on 4 August 2007 on a flat area of mown grass within the Rotorua race course (longitude $176.26^{\circ}$, latitude $-38.15^{\circ}$ ) totally exposed to any prevailing winds. The spray line $(20 \mathrm{~m})$ was oriented at right angles to the wind direction $(\mathrm{N})$. A $5 \mathrm{~m}$ wide spray boom was used to apply either one or four swathes per treatment "block". The single swathe application was $5 \mathrm{~m}$ from the nominal spray block edge; if four swathes were applied then these were respectively 5, 10, 15 and $20 \mathrm{~m}$ from the spray block edge. Seven downwind sampling points were located at $0.5,1.5,3,5,10$, 15 and $20 \mathrm{~m}$ from the first swathe edge. Within spray block deposits (four collectors) were placed near the start and end of the first swathe location so that they received either the spray from a single application or the cumulative spray deposits when four swathes were applied. Deposits outside the spray block were collected on plastic tape strips (commercial safety tape, $10 \mathrm{~cm} \times 3 \mathrm{~m}$ ), pinned to the ground along the mid-line of the sprayed distance and at right angles to the spray line. At the end of the trial these tapes were cut into three sections, and bagged individually to provide three collection replicates for each sampling position.

\section{Equipment and application}

The trial design was based on the International Standard ISO/FDIS 22866 (Anon. 2005). A tractor mounted $5 \mathrm{~m}$ wide boom was used with 10 XR TeeJet 11003 or 11004 flat fan nozzles spaced at $0.5 \mathrm{~m}$ intervals. Operating pressures were 300 and $150 \mathrm{kPa}$ respectively to deliver a nominal 200 litres/ha (calibrated prior to trial with water). The tractor speed was typically $7 \mathrm{~km} / \mathrm{h}$ and boom height $0.4 \mathrm{~m}$ above the top of the grass. Spray solutions were in 50 litre plastic tanks, which were flushed with deionised water after each salt solution treatment. Samples of each spray solution were also taken for analysis to check for any cross contamination. Spray application was in the sequence shown in Table 1 with a total of four applications using each nozzle type. The droplet spectra for each nozzle type and spray solution were obtained beforehand using a Malvern 2600 droplet sizing instrument (800 mm lens) under still air conditions. Representative volume mean diameter (VMD) values were $165 \mu \mathrm{m}$ for the 11003 nozzle and $212 \mu \mathrm{m}$ for 
the 11004 nozzle (pure water was 156 and $193 \mu$ m respectively). The addition of $0.1 \%$ Bond Xtra (a sticker adjuvant) was the reason for the difference from the values for water with and without salt solutions. Meteorological conditions were measured upwind of the spray lines by a $2.0 \mathrm{~m}$ mast $25 \mathrm{~m}$ upwind of the spray zone (wind speed and direction, RH and temperature). Values were means of readings every 30 s (3-12 records).

\section{RESULTS AND DISCUSSION}

Recoveries of cations from the tape were $100 \%, 97.7 \%, 99.9 \%, 101 \%, 91.4 \%$ and $105 \%$ for $\mathrm{Co}, \mathrm{K}, \mathrm{Li}, \mathrm{Mn}, \mathrm{Se}$ and $\mathrm{Mg}$. In the case of $\mathrm{Ba}$ and $\mathrm{Cu}$ the recoveries were $62.1 \%$ and $131.4 \%$. Field spray deposition results from the $\mathrm{Ba}$ and $\mathrm{Cu}$ spray were also anomalous and were rejected. Possible reasons are that the Ba reacted with sulphur from the Rotorua atmosphere and hence recoveries were poor; the source of the irregular copper contamination was not identified unambiguously. All cation concentration data were also corrected for background levels of cations from the tape, which were at analytical limits of detection or very slightly above (for $\mathrm{Mg}$ ) but at higher levels for $\mathrm{Ba}$ and $\mathrm{Cu}$. Other than the $\mathrm{Ba}$ and $\mathrm{Cu}$ solutions, tank spray solution carryover was found to be $0.1 \%$ or less for all other cation solutions.

Examples presented here are from selected spray events (Treatments 6, 7 and 8), as those had the highest wind speeds and were close in sequence so that the other conditions (wind direction, $\mathrm{RH}$ and temperature) were also similar. The spray volumes applied (as determined from within swathe deposits) were respectively 154.8, 158.4 and 164.7 litres/ha.

The deposition profiles from either one swathe or four swathes for the XR 11003 nozzle are shown in Figure 1. The cations used were selenium and magnesium (Treatments 7 and 8). Mean wind speeds were 2.6 (range 1.7 to $3.4 \mathrm{~m} / \mathrm{s}$ ) and 2.8 (range 2.1 to $3.6 \mathrm{~m} / \mathrm{s}$ ) respectively; mean wind direction was $22.8^{\circ}$ and $16.5^{\circ}$ from north; $\mathrm{RH}$ was $78.8 \%$ and $80.6 \%$ and temperature $11.9^{\circ} \mathrm{C}$ and $11.5^{\circ} \mathrm{C}$ respectively. As expected the combined drift deposition from the application of four swathes is more than that from the single application. However, even though the initial selenium cation concentration in the single swathe treatment is 22.6 times less than magnesium (four swathe treatment), it can still be detected equally well due to the higher responses by the ICP-MS instrument. It also shows that this technique is capable of monitoring deposition from single swathe applications using fine droplet nozzles.

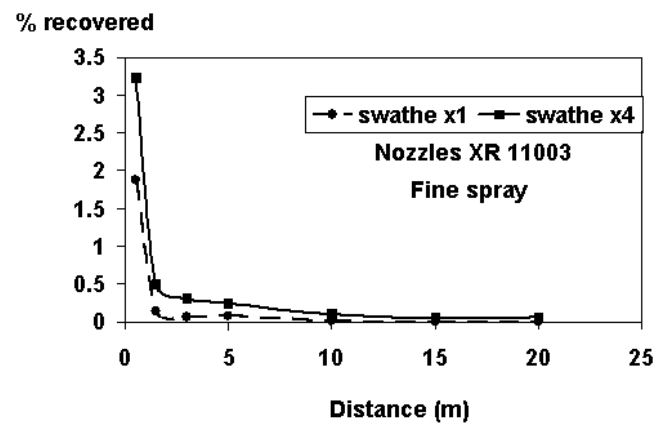

FIGURE 1: Comparison of spray drift deposits between single (selenium, Treatment 7) and multiple (magnesium, Treatment 8) swathe applications with fine spray XR 11003 nozzles. Wind speeds were 2.6 and $2.8 \mathrm{~m} / \mathrm{s}$ respectively.

The traces in Figure 2 represent a comparison of the drift from the XR 11003 (fine spray) and XR 11004 (medium spray) using manganese and magnesium tracers, with mean wind speeds of 1.6 (range 1.1 to $2.2 \mathrm{~m} / \mathrm{s}$ ) and 2.8 (range 2.1 to $3.6 \mathrm{~m} / \mathrm{s}$ ); mean wind direction was $24^{\circ}$ and $16.5^{\circ}$ from north; $\mathrm{RH}$ was $77.8 \%$ and $80.6 \%$ and temperature 
$11.8^{\circ} \mathrm{C}$ and $11.5^{\circ} \mathrm{C}$ respectively. This shows that the much greater drift from the fine spray, though at a lower wind speed, is easily detectable at $20 \mathrm{~m}$ from the edge of the spray block. The amount detected there was $0.06 \%$ of the spray, equivalent to $0.008 \mathrm{ppm}$ in the recovered sample. Since the limit of detection is $0.0005 \mathrm{ppm}$ for $\mathrm{Mn}$, there is still an extra 10-fold detection capability. Even in the case of $\mathrm{Mg}$ with the detection limit being $0.02 \mathrm{ppm}$, the $0.06 \%$ also detected at the same point, corresponds to $0.23 \mathrm{ppm}$ and a further ten-fold detection capability is again possible.

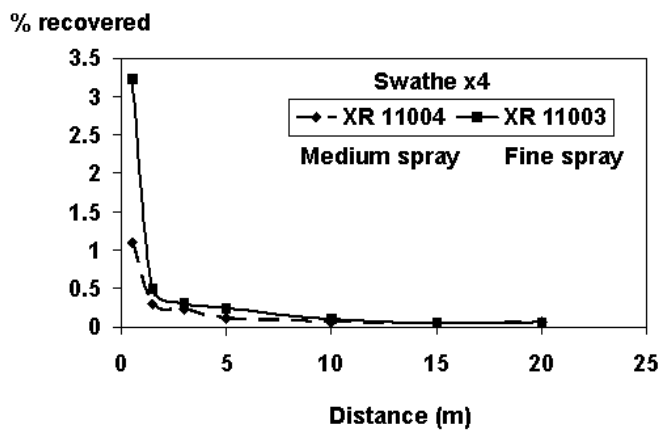

FIGURE 2: Comparison of spray drift deposits from multiple swathe applications between medium spray XR 11004 (manganese, Treatment 6) and fine spray XR 11003 (magnesium, Treatment 8) nozzles Wind speeds were 1.6 and $2.8 \mathrm{~m} / \mathrm{s}$ respectively.

The use of metal cations as tracers in spray drift studies has been tried before but has encountered difficulties (background interference from artificial targets with $\mathrm{LiCl}$ (Thistle et al. 2007)) or using $\mathrm{NaCl}$, which is inappropriate for field studies (Brusselman et al. 2004). Metal chelates of $\mathrm{Cu}, \mathrm{Mn}$ and $\mathrm{Zn}$ have also been used and recoveries from plastic lines were excellent but were somewhat less from fruit and leaves. Strontium was found to be unsatisfactory due to low recoveries from plants. These studies also demonstrated equivalent deposition results between the cations and tartrazine dye (Cross et al. 2001). Analysis of cations was by atomic absorption spectroscopy of each cation individually, which meant a large workload.

Current analytical technology based on simultaneous multi-cation quantification by ICP-MS is a much more attractive and cost effective approach. Sensitivity and selectivity is high to many metal cations, so only small amounts are required in the spray solution and can be less than that required with tartrazine dye (typically $10 \mathrm{~g} /$ litre). Deposited amounts are much less and such amounts are not expected to be phytotoxic to plants, though this trial did not address this specifically. The advantages of using metal salt solutions are that they are readily water soluble (no need for chelates), deposits are stable to light and temperature, and organic contaminants are not a problem during extraction or analysis.

Nozzle droplet spectra quoted in the literature are mainly for pure water solutions, and the addition of cation salts does not affect this. In contrast, adjuvants, which create a non-Newtonian fluid, can affect the droplet spectrum (Spanoghe et al. 2007). If metal cation solutions are used then manufacturer's nozzle droplet spectra can be used without having to re-measure spray characteristics. If an adjuvant such as Bond Extra is required, the amount added is very small and changes to spectra are also small.

The overwhelming advantage of using cation tracers is that the same collectors or samplers can be used throughout a series of spray events. This reduces experimental set-up time, reduces sample collection time and many fewer collectors need to be extracted. In this trial involving two deposition areas of eight spray events each, with seven downwind sampling points and three replicate collectors along the sampling line for each deposition area (a total of 336 data points), only 42 deposit collectors needed to be uplifted and analysed once. Extracts from the collectors can be stored frozen virtually indefinitely 
without fear of degradation. The novel advantages of flexible plastic tapes are that they are cheap and readily available, come in a standard width and can be processed in sections or in toto. They can provide at least a 3-fold increase for each collector surface area compared to the use of stainless steel or glass plates. Since the tape is light and flexible, long lengths can be placed easily in plastic bags to which the extraction solution can be added, thereby reducing laboratory equipment costs.

Cations as tracers for spray drift studies (with or without adjuvants) could be used in place of agrichemical sprays as they would be non-phytotoxic. Although plant foliage can be analysed in toto, background levels for each plant sampled would need to be determined and tracers selected to prevent significant interference with naturally abundant metal cations. Plant surface areas may need to be determined so some extra effort would be required.

\section{CONCLUSIONS}

It has been demonstrated that spray drift studies can be undertaken using metal cations as the tracers. This has the advantage of using the same collector throughout multiple spray events, and consequently reducing the time and cost associated with such trials. The convenience of such easy replication can provide more data sets, which in turn can be used more effectively in further spray drift model development or validation.

\section{ACKNOWLEDGEMENTS}

This work was funded by the New Zealand Foundation for Research, Science and Technology (Contract LVLX0304). The assistance during the trial and sample processing by B. Moorhead, S. Gous, D. Horgan, M. Geddes and A. Pathan is gratefully acknowledged. Analyses were by R.J. Hill, Hamilton, and constructive reviews by B. Richardson and W. A. Forster.

\section{REFERENCES}

Anon. 2005. ISO 22866. Equipment for crop protection - methods for field measurement of spray drift. International Organisation for Standardisation, Tech Committee ISO/ TC 23. Tractors and machinery for agriculture and forestry, Subcommittee SC6. Equipment for Crop Protection. Geneva, Switzerland.

Brown RB, Carter MH, Stephenson GR 2004. Buffer zone and windbreak effects on spray drift deposition in a simulated wetland. Pest Management Science 60: 1085-1090.

Brusselman E, Spanoghue P, Steurbaut W, Van der Meeren P, Gabriels D 2004. Wind tunnel evaluation of a drift model using a NaCl-solution as tracer. Aspects of Applied Biology 71: 467-472.

Cross JV, Walklate PJ, Murray RA, Richardson GM 2001. Spray deposits and losses in different sized apple trees from an axial fan orchard sprayer: 1. Effects of spray liquid flow. Crop Protection 20: 13-30.

Gil Y, Sinfort C 2005. Emission of pesticides to the air during sprayer application: a bibliographic review. Atmospheric Environment 39: 5183-5193.

Spanoghe P, De Schampheleire M, Van der Meeren P, Steurbaut W 2007. Influence of adjuvants on droplet spectra. Pest Management Science 63: 4-16

Teske ME, Valcore DL, Hewitt AJ 2001. An analytical ground sprayer model. Presented at American Society of Agricultural Engineers International Meeting, Sacramento, California, 30 July-1 August 2001.

Thistle HW, Ice G, Karsky R 2007. Spray capture by a riparian barrier. In: American Society of Agricultural and Biological Engineers, Minneapolis, USA. Paper No. 071148, ASABE meeting, Minneapolis, USA, 17-20 June.http://asae.frymulti.com/ request.asp (accessed October 2007).

Ucar T, Hall FR, Tew JE, Hacker JK 2003. Wind tunnel studies on spray deposition on leaves of tree species used for windbreaks and exposure of honey bees. Pest Management Science 59: 358-364.

Woodward SJR, Connell RJ, Zabkiewicz JA, Steele KD, Praat JP 2008. Evaluation of the AGDISP ground boom spray drift model. New Zealand Plant Protection 61: 164-168. 